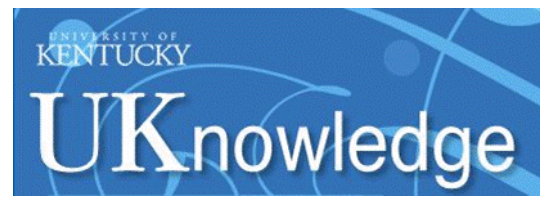

University of Kentucky

UKnowledge

\title{
Impact of Nutrition on Pollutant Toxicity: An Update with New Insights Into Epigenetic Regulation
}

\author{
Jessie B. Hoffman \\ University of Kentucky, jessie.hoffman@uky.edu \\ Michael C. Petriello \\ University of Kentucky, michaelcpetriello@gmail.com \\ Bernhard Hennig \\ University of Kentucky, bhennig@uky.edu
}

Follow this and additional works at: https://uknowledge.uky.edu/superfund_facpub

Part of the Environmental Health and Protection Commons, Genetics and Genomics Commons, and the Nutrition Commons

Right click to open a feedback form in a new tab to let us know how this document benefits you.

\section{Repository Citation}

Hoffman, Jessie B.; Petriello, Michael C.; and Hennig, Bernhard, "Impact of Nutrition on Pollutant Toxicity: An Update with New Insights Into Epigenetic Regulation" (2017). Superfund Research Center Faculty Publications. 4.

https://uknowledge.uky.edu/superfund_facpub/4

This Review is brought to you for free and open access by the Superfund Research Center at UKnowledge. It has been accepted for inclusion in Superfund Research Center Faculty Publications by an authorized administrator of UKnowledge. For more information, please contact UKnowledge@lsv.uky.edu. 


\title{
Impact of Nutrition on Pollutant Toxicity: An Update with New Insights Into Epigenetic Regulation
}

\author{
Digital Object Identifier (DOI) \\ https://doi.org/10.1515/reveh-2016-0041 \\ Notes/Citation Information \\ Published in Reviews on Environmental Health, v. 32, issue 1-2, p. 65-72. \\ (C2017 Walter de Gruyter GmbH, Berlin/Boston.
}

The copyright holder has granted the permission for posting the article here.

This review is available at UKnowledge: https://uknowledge.uky.edu/superfund_facpub/4 


\section{Review}

Jessie B. Hoffman, Michael C. Petriello and Bernhard Hennig*

\section{Impact of nutrition on pollutant toxicity: an update with new insights into epigenetic regulation}

DOI 10.1515/reveh-2016-0041

Received August 9, 2016; accepted November 9, 2016; previously published online January 11, 2017

Abstract: Exposure to environmental pollutants is a global health problem and is associated with the development of many chronic diseases, including cardiovascular disease, diabetes and metabolic syndrome. There is a growing body of evidence that nutrition can both positively and negatively modulate the toxic effects of pollutant exposure. Diets high in proinflammatory fats, such as linoleic acid, can exacerbate pollutant toxicity, whereas diets rich in bioactive and anti-inflammatory food components, including omega-3 fatty acids and polyphenols, can attenuate toxicant-associated inflammation. Previously, researchers have elucidated direct mechanisms of nutritional modulation, including alteration of nuclear factor kappa-lightchain-enhancer of activated B cells (NF- $\mathrm{B}$ ) signaling, but recently, increased focus has been given to the ways in which nutrition and pollutants affect epigenetics. Nutrition has been demonstrated to modulate epigenetic markers that have been linked either to increased disease risks or to protection against diseases. Overnutrition (i.e. obesity) and undernutrition (i.e. famine) have been observed to alter prenatal epigenetic tags that may increase the risk of offspring developing disease later in life. Conversely, bioactive food components, including curcumin, have been shown to alter epigenetic markers that suppress the activation of NF- $\kappa \mathrm{B}$, thus reducing inflammatory responses. Exposure to pollutants also alters epigenetic markers and

\footnotetext{
* Corresponding author: Bernhard Hennig, Superfund Research Center, University of Kentucky, 900 S. Limestone Street, Lexington, KY 40536, USA, Tel.: +1 859-218-1343, Fax: +1 859-257-1811, E-mail: bhennig@uky.edu; and Department of Animal and Food Sciences, College of Agriculture, Food and Environment, University of Kentucky, Lexington, KY 40536, USA Jessie B. Hoffman: Superfund Research Center, University of Kentucky, Lexington, KY 40536, USA; and Department of Pharmacology and Nutritional Sciences, College of Medicine, University of Kentucky, Lexington, KY 40536, USA

Michael C. Petriello: Superfund Research Center, University of Kentucky, Lexington, KY 40536, USA; and Department of Animal and Food Sciences, College of Agriculture, Food and Environment, University of Kentucky, Lexington, KY 40536, USA
}

may contribute to inflammation and disease. It has been demonstrated that pollutants, via epigenetic modulations, can increase the activation of NF- $\kappa \mathrm{B}$ and upregulate microRNAs associated with inflammation, cardiac injury and oxidative damage. Importantly, recent evidence suggests that nutritional components, including epigallocatechin gallate (EGCG), can protect against pollutant-induced inflammation through epigenetic regulation of proinflammatory target genes of NF- $\mathrm{BB}$. Further research is needed to better understand how nutrition can modulate pollutant toxicity through epigenetic regulation. Therefore, the objective of this review is to elucidate the current evidence linking epigenetic changes to pollutant-induced diseases and how this regulation may be modulated by nutrients allowing for the development of future personalized lifestyle interventions.

Keywords: anti-inflammatory nutrients; antioxidant response; environmental pollutants; epigenetics; nutrition.

\section{Introduction}

The levels of environmental pollutants continue to rise worldwide, despite our increasing knowledge base of the negative health effects of pollutant exposure. There is increasing evidence that exposure to pollutants, including persistent organic pollutants (POPs), heavy metals and air pollution, can contribute to the progression of chronic diseases such as cardiovascular disease (CVD), diabetes and cancer. Currently, the strongest evidence linking POPs with inflammatory diseases is related to pollutant-induced diabetes $(1,2)$. Multiple meta-analyses show positive associations of exposures to POPs such as polychlorinated biphenyls (PCBs) and pesticides with increased risk of developing type 2 diabetes $(1,2)$. The health effects of pollutant exposure not only pose a problem for the individual but also contribute to the global burden of disease.

The mechanisms by which many of these pollutants contribute to disease involve an increase in cellular oxidative stress and subsequent inflammatory responses. For example, coplanar PCBs, a class of POPs, increase downstream inflammatory responses by binding to the aryl hydrocarbon receptor, 
which can upregulate the transcription of cytochrome $\mathrm{p} 450$ (Cyp1a1) (3, 4). Cyp1a1 is primarily involved in xenobiotic detoxification; however, in the presence of certain PCBs, it results in the production of reactive oxygen species (ROS) via an uncoupling mechanism (5). This production of ROS yields an increase in oxidative stress because of the imbalance in the cellular redox status (4). This pro-oxidative cellular status contributes to a state of chronic inflammation, which is a hallmark of many diseases, including atherosclerosis, diabetes and other metabolic disorders (6).

The most common routes of exposure to these environmental pollutants are through inhalation of airborne pollutants as well as ingestion of contaminated foods (7). POPs, including PCBs and organochloride pesticides, are lipophilic and therefore readily accumulate in the tissue of living animals (8). Although the production of many of these pollutants has been banned, their resistance to degradation and stability in the environment have allowed for their bioaccumulation throughout the ecosystem (8). Additionally, in humans, the accumulation of these lipophilic pollutants over the course of many years can lead to the activation of inflammatory pathways contributing to the development of numerous chronic inflammatory diseases $(9,10)$. Obesity is linked to higher pollutant body burden, but there is no consensus if obesity makes a person more or less susceptible to pollutant-induced disease. Interestingly, there is some experimental evidence that points to the sequestration of pollutants in large adipose depots as actually being protective (11-13). Lipophilic pollutants may accumulate within adipocytes and lipid droplets, which limits their availability to other target cell types. Importantly, it appears that obese individuals undergoing weight loss through either bariatric surgery or lifestyle intervention may be a highly susceptible population to pollutant-induced inflammation (11-13). Because overweight and obese individuals are not only capable of accumulating greater levels of pollutants but also already at an increased risk for developing chronic inflammatory diseases, dietary interventions that provide a means of combatting pollutant toxicity and chronic disease risk factors are of great importance. $(8,14,15)$.

\section{Nutrition as a modulator of pollutant toxicity}

\section{Poor nutrition can exacerbate the toxicity of pollutants}

It is well established that exposure to environmental pollutants can increase risk of developing chronic inflammatory diseases, including CVD, diabetes, and metabolic syndrome (6-9). Additionally, evidence implicates that individuals with a less nutritious or healthful diet (i.e. rich in processed foods and low in fruits and vegetables) are also at a greater risk of developing these same chronic diseases (16). Common to both pollutant exposure and poor nutrition is the activation of proinflammatory molecular proteins, including NF- $\kappa B$, a key player in the development of inflammatory responses (17). Because of the overlap between pathways that mediate the negative effects of poor nutrition and environmental pollutants, there is an increasing body of experimental evidence demonstrating that certain nutritional components or overall nutritional status can exacerbate the negative health effects of environmental pollutant exposure.

Obesity is a global health problem and is a risk factor for the development of numerous inflammatory diseases (18). The rise in obesity is often attributed to overconsumption of processed, nutritionally poor foods (i.e. high energy density and low nutrient density) and foods high in proinflammatory fats (18). It has been consistently demonstrated that high fat diets, particularly those with greater proportions of fatty acids coming from saturated, trans, and linoleic fatty acids can increase inflammation and risk of CVD as well as other metabolic complications $(19,20)$. In addition to overconsumption of nutritionally poor foods, emerging evidence now links exposure to environmental pollutants with increased adiposity and weight gain (21). Pollutants that elicit this physiological effect are termed "obesogens" and are believed to contribute to obesity and metabolic disorder through promotion of chronic imbalances in lipid storage mechanisms and adipocyte hyperplasia (21). Current evidence suggests that pollutant exposure can intensify the detrimental effects of a proinflammatory high-fat diet (22). For example, non-alcoholic fatty liver disease (NAFLD), commonly seen in developed countries as a hepatic indicator of obesity and metabolic syndrome, may be worsened by pollutant exposure. It has been demonstrated that the pollutant PCB153 exacerbates diet-induced obesity and NAFLD in mice through alterations in adipokines and disruptions in hepatic lipid metabolism (23). Additionally, high-fat diets appear to worsen arsenic-induced liver fibrosis and inflammation (24), whereas diets high in saturated fat appear to increase the toxicity and carcinogenic effects of POPs (25). Furthermore, the flame retardant hexobromocyclododecane, was observed to enhance high-fat diet-induced obesity and hepatic steatosis and to impair glucose and lipid homeostasis in mice (26). 
Cardiovascular diseases (CVDs) are the leading cause of death worldwide, and it is estimated that approximately $90 \%$ of CVDs can be prevented (27). The primary modifiable risk factors contributing to the development of CVDs include poor dietary habits, physical inactivity, and smoking (27). Similarly, to the development of obesity, diets containing certain fatty acid profiles may promote the development of CVDs. For example, consumption of proinflammatory fatty acids such as linoleic and transfatty acids can contribute to endothelial cell dysfunction, a beginning stage of atherosclerosis $(19,20)$. Additionally, it has been demonstrated, primarily in experimental models, that exposure to environmental pollutants can cause endothelial cell dysfunction and chronic inflammation and may contribute to the development of CVDs $(3,28,29)$. Furthermore, there is increasing experimental evidence that poor nutrition and pollutant exposure can interact and synergistically increase CVD risk (30). For example, it has recently been shown that trimethylamine $\mathrm{N}$-oxide (TMAO), produced from the metabolism of dietary carnitine or phosphatidyl choline, is a strong clinical biomarker of CVD (31-35). Interestingly, a recent preclinical paper from our group found that dioxin-like pollutant exposure increases the hepatic expression of the enzyme flavin-containing monooxygenase (FMO3), which is critical for the production of TMAO. As such, this increase in the hepatic expression of FMO3 resulted in increases in circulating TMAO (36). Although this study was conducted in mice and the transcriptional regulation of FMO3 could differ in humans, this finding is important in that it provides new evidence on how certain nutritional components and pollutants may interact to contribute to a greater risk of CVD.

It is not surprising that pollutant exposure exhibits detrimental combinatory effects with suboptimal nutrition as pollutants and nutritional components can target the same molecular pathways, for example, the proinflammatory NF- $\mathrm{KB}$ pathway (4). However, this same idea can be used from the perspective of nutrition as a protective modulator of pollutant toxicity and may be more meaningful for those already exposed to high levels of pollutants and exhibiting signs of chronic inflammatory diseases.

\section{Healthful nutrition can protect against the health effects of pollutant exposure}

It is well understood that a nutritious diet, rich in foods containing bioactive food components such as polyphenols and anti-inflammatory fatty acids, can be protective against chronic inflammation, diabetes, metabolic syndrome, and CVD (16). Diets rich in these bioactive food components often contain greater levels of antioxidant and anti-inflammatory compounds and thus have the capacity to attenuate the inflammatory and oxidative properties of pollutant exposure. This paradigm has been demonstrated consistently throughout the literature (3743). For example, we have shown that consumption of polyphenol-rich green tea can decrease oxidative stress in response to PCB 126 exposure and does so via upregulation of antioxidant enzymatic pathways (38). Additionally, it has been observed that epigallocatechin gallate (EGCG), a major polyphenol in green tea, can attenuate arsenicinduced cardiovascular inflammation and toxicity (42). Resveratrol, a polyphenol found abundantly in fruits and other plants, has been demonstrated to protect against PCB-induced neuronal cell death as well as impairment in adipocyte glucose homeostasis $(44,45)$.

Omega-3 polyunsaturated fatty acids, including eicosapentaenoic acid and docosahexaenoic acid, found abundantly in fatty fish and fish oil, exhibit potent antiinflammatory properties $(46,47)$. Indeed, individuals consuming a diet abundant in omega-3 fatty acids, such as the well-studied Mediterranean diet, are documented as having lower incidences of CVD, diabetes, and metabolic syndrome (48). It is not surprising then, that experimental evidence shows that omega- 3 fatty acids can be protective against pollutant-induced inflammation and toxicity. As such, we have demonstrated that omega-3 fatty acids can protect against PCB-induced vascular endothelial cell dysfunction (37), and others have shown that these fatty acids can protect against pollutant-associated atherosclerotic plaque formation (49). Additionally, omega-3 fatty acids appear to be protective against air pollutant-associated oxidative stress and cardiovascular complications by increasing the activity of endogenous antioxidants and decreasing lipoperoxidation $(40,43)$.

In addition to consuming a diet rich in polyphenols and anti-inflammatory components, choosing to live an active lifestyle may also protect against pollutant toxicity. For example, a recent study by our laboratory observed that exercise is capable of reducing inflammation and CVD risk associated with PCB exposure (50). Furthermore, other groups have demonstrated that exercise can attenuate PCB-associated alterations in the mouse gut microbiome (51). This is an important finding because the gut microbiome has recently been observed to regulate numerous health conditions, including obesity, CVD, immune function, and neurological disorders (52-54). Importantly, the gut microbiome is incredibly plastic and can change rapidly in response to nutrition, exercise, 
and even pollutant exposure (52-54). Using nutrition and exercise to combat pollutant-induced alterations in the gut microbiome that may contribute to disease may allow for important advances in therapeutic interventions and is a critical area of research that needs to be further explored.

Because many of these environmental pollutants are lipophilic and accumulate within the adipose tissue of exposed individuals, examining nutritional means to promote the excretion and reduction of body burden is an important facet as well. It has been noted that individuals consuming a vegetarian or vegan diet trended towards lower amounts of organochloride body burden (55). However, it remains unclear whether this observation was due to less exposure to contaminated foods (e.g. contaminated meats, fish, or dairy) or whether a plant-based diets contain nutritional components that can promote excretion of these pollutants. Although further research is still warranted to examine nutritional means by which to reduce pollutant body burden, some studies have indicated promising opportunities for therapeutic interventions in exposed individuals (56-58). Specifically, it has been observed that consumption of olestra, a dietary fat substitute, is effective at enhancing the excretion rate in individuals exposed to high concentrations of PCBs and is believed to do so through interference with the enterohepatic circulation of these pollutants (58-62). Because olestra is no longer in production due to decreased popularity associated with adverse gastrointestinal side effects, there is a need for research examining other dietary components that may alter enterohepatic circulation and/or enhance pollutant excretion. As discussed, it is well documented that nutrition and lifestyle choices can both positively and negatively regulate pollutant toxicity. Recently, the field of epigenetics has become important in furthering our understanding how environment and lifestyle choices differentially influence gene expression and may alter susceptibility to disease on an individual level.

\section{Epigenetics as an emerging area of pollutant toxicity research and avenue for future intervention}

\section{Epigenetics overview}

Epigenetics is a term given to describe all heritable changes in gene expression that do not involve changes within the genetic code (63). One of the most commonly studied means of epigenetic modifications is DNA methylation, which involves the addition of a methyl group to the five position of a cytosine. This modification most often occurs on a cytosine-guanine dinucleotide ( $\mathrm{CpG}$ ). $\mathrm{CpG}$ dinucleotides tend to be clustered in certain regions, termed $\mathrm{CpG}$ islands, and are often located in the promoter regions of protein-coding genes $(63,64)$. DNA methylation is involved in the regulation of numerous cellular processes, ranging from chromosome stability, to X-chromosome inactivation, to gene transcription. Generally, the hypermethylation of $\mathrm{CpG}$ islands within the promoter regions results in gene silencing. Another common type of epigenetic alteration includes histone modifications. Histones are nuclear proteins that aid in the condensation of DNA into structural units called nucleosomes. Histones can undergo posttranslational modifications such as acetylation, methylation, and phosphorylation, which affect the interactions of histones with the DNA and associated nuclear proteins (63). Through these histone modifications, alterations in chromatin structure and subsequently gene expression are often observed $(63,64)$. A third major type of epigenetic modification involves microRNAs (miRNAs). miRNAs are small single-stranded noncoding RNA molecules that when fully mature lead to the degradation of target mRNA by direct binding. This downregulation of target mRNAs can ultimately lead to decreased protein production. miRNAs regulate numerous biological processes, and it has been observed that alterations in miRNA expression are associated with the development of diseases such as CVD, metabolic disorders and cancer (63-65).

Environment and lifestyle play critical roles in contributing to the epigenetic alterations discussed above (65). Studies on monozygotic twin pairs have demonstrated that throughout the aging process, identical twins develop differences in their epigenetic status despite their common genetic makeup (63). These observations and the knowledge that differences in epigenetic modifications can play a role in disease contributed to increasing interest in examining the ways and extent to which our environment influences our epigenetic code.

\section{Epigenetics, environmental exposures and nutrition}

It has been consistently demonstrated that exposure to environmental pollutants can influence epigenetic modifications (65-69). Specifically, exposure to POPs can alter the epigenetic code through several mechanisms. For example, we have demonstrated that exposure to coplanar 
PCBs, including PCB 77 and PCB126, can induce vascular endothelial cell dysfunction and inflammation through alterations in histone modifications of the p65 subunit of NF- $\kappa B$ that result in its increased activation (66). Additionally, we have shown that the commercial PCB mixture Aroclor 1260 can upregulate miRNAs associated with cardiac injury and inflammatory pathways in primary human endothelial cells (69). In humans, it has been observed that exposure to polyaromatic hydrocarbons $(\mathrm{PAH})$ results in alterations in specific miRNAs associated with oxidative DNA damage and lipid peroxidation in coke oven workers (67). Moreover, it was noted that exposure to air pollution was associated with expression of miRNAs that may mediate detrimental biological responses and health effects (68).

One common theme with many pollutant-associated epigenetic alterations is that they induce modifications that contribute to proinflammatory and oxidative pathways $(65,70)$. Interestingly, nutrition and positive lifestyle choices can also contribute to epigenetic modifications that may combat these detrimental effects by increasing antioxidant and anti-inflammatory responses (71, 72). Polyphenolic compounds found in many fruits and vegetables exhibit significant antioxidant and antiinflammatory capacities and thus are good candidates for studies examining epigenetic means of protection against pollutant toxicity. For example, curcumin, a component found in turmeric that exhibits anti-inflammatory properties, has been observed to reduce histone acetylation of the $N F-\kappa B$ coactivator p300 histone acetyltransferase and thus suppress the activation of NF- $\kappa B$ (73). Similar results were observed by our group with the tea catechin EGCG (74). Furthermore, it has been reported that numerous polyphenols can activate SIRT1, a member of the sirtuin family of histone deacetylases. When activated, SIRT1 can participate in the deacetylation of transcription factors such as NF- $\mathrm{kB}$, forkhead box class O (FoxO) and $\mathrm{p} 53$, in turn modulating cellular pathways involved in inflammation, metabolism, aging, and several other conditions (71).

In addition to healthful nutrition, physical exercise also contributes to epigenetic modifications that may provide protection against metabolic, cardiovascular, and other diseases. For example, one study found that acute exercise resulted in changes in the methylation of the promoter region of genes involved in energy and glucose homeostasis, including pyruvate dehydrogenase kinase isoenzyme 4 (PDK4), peroxisome proliferator-activated receptor gamma coactivator 1-alpha $(P C G 1 \alpha)$, and peroxisome proliferator-activated receptor delta $(P P A R \delta)$ within skeletal muscle (75). Furthermore, physical exercise was observed to inhibit the miRNA miR-33 $(76,77)$. Cellular effects of miR-33 inhibition involve the upregulation of $A M P K$ and subsequent increases in $\beta$-oxidation, which may aid in balancing factors related to metabolic syndrome by increasing the breakdown of fatty acids from adipose stores (77). The role of $\beta$-oxidation in metabolic syndrome is complex and is influenced by both dietary components and exercise, leading to an increase in fatty acid oxidation and ultimately decreased obesity and metabolic syndrome (78-80). Understanding the role of miRNAs in lipid homeostasis may provide potential therapeutic strategies for reducing metabolic syndrome.

Although epigenetics can be modulated by healthful nutrition and positive lifestyle choices, there is also evidence that epigenetics can be modified by poor nutrition. Epidemiological data are very helpful at examining epigenetic alterations, as there appears to be inheritance to specific DNA methylation patterns over generations. For example, it has been shown that individuals who were prenatally exposed to famine during the Dutch famine (1940s) had reduced DNA methylation of the insulin-like growth factor II (IGF2) gene six decades later, compared to their siblings who were unexposed to the famine (81). Also, it has been demonstrated that parental obesity can alter DNA methylation patterns in imprinted genes of their offspring, compared to offspring of nonobese parents, and this is believed to increase the risk for the development of obesity and metabolic diseases later in life (82). Although there is still much to be studied about the effects of these alterations related to epigenetic modifications, it is hypothesized that in both cases of undernutrition and over-nutrition, the acquired epigenetic alterations may be passed down to the subsequent generation and may increase susceptibility to development of chronic diseases throughout life (81-83).

The epigenetic alterations in response to nutrition and lifestyle choices have been well documented; however, studies examining the epigenetic effects of nutritional components on the modulation of pollutant toxicity are limited. A recent study conducted by our group showed that EGCG, the most abundant polyphenol found in green tea, can prevent against PCB126-induced endothelial cell inflammation through epigenetic alterations of proinflammatory target genes of NF- $\mathrm{kB}$ (74). This study was important in that it was one of the first studies to indicate the epigenetic role of healthful nutrition in the modulation of pollutant toxicity. Because of the gaps in the literature regarding epigenetic regulation of pollutant toxicity via nutritional and lifestyle interventions, there is a great need for further research to formulate a better understanding of this topic. 


\section{Conclusion and future directions}

Environmental pollutant exposure is associated with numerous health complications ranging from cardiovascular disease, diabetes, and metabolic syndrome. There is evidence that pollutant toxicity can be modulated by nutrition and lifestyle choices. Western diets, abundant in processed foods, excess caloric content and proinflammatory fatty acids, may contribute to the development of obesity and, cardiovascular diseases and can enhance pollutant toxicity. Conversely, diets rich in bioactive food components, such as polyphenols and omega-3 fatty acids (i.e. the Mediterranean diet), are associated with reduced risk of inflammatory diseases and can attenuate the negative health effects of pollutant exposure. Recently, epigenetics has become a focus of both nutrition and pollutant research and may provide a deeper mechanistic insight into how these two environmental factors can interact. It has been shown that both over- and undernutrition can contribute to epigenetic modifications that are associated with an increased risk of disease. Additionally, exposure to pollutants can alter epigenetic markers that may also contribute to the development of health complications. Importantly, we have shown that bioactive food components (e.g. EGCG) can induce epigenetic alterations that attenuate inflammatory responses associated with PCB exposure and thus may protect against the development atherosclerosis. Epigenetic marks differ for every individual, and therefore future studies may allow us to understand how certain foods may be used to alter specific epigenetic tags to reduce the risk of pollutant-associated disease. Future studies also need to focus on metabolites of both pollutants and nutrients and the complex interplay of epigenetic regulation of chronic diseases. Fostering an understanding at this detailed level could help in developing personalized nutritional interventions that could epigenetically favor good health and thus reduce the risk of disease.

Research funding: This work was supported by the National Institute of Environmental Health Sciences at the National Institutes of Health [P42ES007380], and the University of Kentucky Agricultural Experiment Station.

Conflict of interests: The authors declare that there are no competing financial interests.

\section{References}

1. Tang M, Chen K, Yang F, Liu W. Exposure to organochlorine pollutants and type 2 diabetes: a systematic review and meta-analysis. PLoS One 2014;9(10):e85556.
2. Taylor KW, Novak RF, Anderson HA, Birnbaum LS, Blystone C, et al. Evaluation of the association between persistent organic pollutants (POPs) and diabetes in epidemiological studies: a national toxicology program workshop review. Environ Health Perspect 2013;121(7):774-83.

3. Lim EJ, Majkova Z, Xu S, Bachas L, Arzuaga X, et al. Coplanar polychlorinated biphenyl-induced CYP1A1 is regulated through caveolae signaling in vascular endothelial cells. Chem-Biol Interact 2008;176(2-3):71-8.

4. Majkova Z, Smart E, Toborek M, Hennig B. Up-regulation of endothelial monocyte chemoattractant protein-1 by coplanar PCB77 is caveolin-1-dependent. Toxicol Appl Pharm 2009;237(1):1-7.

5. Schlezinger JJ, Struntz WD, Goldstone JV, Stegeman JJ. Uncoupling of cytochrome $\mathrm{P} 4501 \mathrm{~A}$ and stimulation of reactive oxygen species production by co-planar polychlorinated biphenyl congeners. Aquat Toxicol 2006;77(4):422-32.

6. Kuehn BM. Environmental pollutants tied to atherosclerosis. J Am Med Assoc 2011;306(19):2081.

7. Carpenter DO. Polychlorinated biphenyls (PCBs): routes of exposure and effects on human health. Rev Environ Health 2006;21(1):1-23.

8. Dirinck E, Jorens PG, Covaci A, Geens T, Roosens L, et al. Obesity and persistent organic pollutants: possible obesogenic effect of organochlorine pesticides and polychlorinated biphenyls. Obesity 2011;19(4):709-14.

9. Goncharov A, Pavuk M, Foushee HR, Carpenter DO. Blood pressure in relation to concentrations of $\mathrm{PCB}$ congeners and chlorinated pesticides. Environ Health Perspect 2011;119(3):319-25.

10. Sergeev AV, Carpenter DO. Hospitalization rates for coronary heart disease in relation to residence near areas contaminated with persistent organic pollutants and other pollutants. Environ Health Perspect 2005;113(6):756-61.

11. Baker NA, Karounos M, English V, Fang J, Wei Y, et al. Coplanar polychlorinated biphenyls impair glucose homeostasis in lean C57BL/ 6 mice and mitigate beneficial effects of weight loss on glucose homeostasis in obese mice. Environ Health Perspect 2013;121(1):105-10.

12. Dirinck E, Dirtu AC, Jorens PG, Malarvannan G, Covaci A, et al. Pivotal role for the visceral fat compartment in the release of persistent organic pollutants during weight loss. J Clin Endocr Metab 2015;100(12):4463-71.

13. Kim MJ, Marchand P, Henegar C, Antignac JP, Alili R, et al. Fate and complex pathogenic effects of dioxins and polychlorinated biphenyls in obese subjects before and after drastic weight loss. Environ Health Perspect 2011;119(3):377-83.

14. Uemura H, Arisawa K, Hiyoshi M, Kitayama A, Takami H, et al. Prevalence of metabolic syndrome associated with body burden levels of dioxin and related compounds among Japan's general population. Environ Health Perspect 2009;117(4):568-73.

15. La Merrill M, Emond C, Kim MJ, Antignac JP, Le Bizec B, et al. Toxicological function of adipose tissue: focus on persistent organic pollutants. Environ Health Perspect 2013;121(2):162-9.

16. Chiuve SE, Sampson L, Willett WC. The association between a nutritional quality index and risk of chronic disease. Am J Prev Med 2011;40(5):505-13.

17. Wang L, Reiterer G, Toborek M, Hennig B. Changing ratios of omega- 6 to omega-3 fatty acids can differentially modulate 
polychlorinated biphenyl toxicity in endothelial cells. Chem-Biol Interact 2008;172(1):27-38.

18. Kopelman PG. Obesity as a medical problem. Nature 2000;404(6778):635-43.

19. Baum SJ, Kris-Etherton PM, Willett WC, Lichtenstein AH, Rudel LL, et al. Fatty acids in cardiovascular health and disease: a comprehensive update. J Clin Lipidol 2012;6(3):216-34.

20. Kuipers RS, de Graaf DJ, Luxwolda MF, Muskiet MH, Dijck-Brouwer DA, et al. Saturated fat, carbohydrates and cardiovascular disease. Neth J Med 2011;69(9):372-8.

21. Grun F. Obesogens. Curr Opin Endocrinol Diabetes, Obes 2010;17(5):453-9.

22. Hennig B, Slim R, Toborek M, Robertson LW. Linoleic acid amplifies polychlorinated biphenyl-mediated dysfunction of endothelial cells. J Biochem Mol Toxicol 1999;13(2):83-91.

23. Wahlang B, Falkner KC, Gregory B, Ansert D, Young D, et al. Polychlorinated biphenyl 153 is a diet-dependent obesogen that worsens nonalcoholic fatty liver disease in male C57BL6/J mice. J Nutr Biochem 2013;24(9):1587-95.

24. Wu J, Liu J, Waalkes MP, Cheng ML, Li L, et al. High dietary fat exacerbates arsenic-induced liver fibrosis in mice. Exp Biol Med 2008;233(3):377-84

25. Harris DL, Washington MK, Hood DB, Roberts LJ, 2nd, Ramesh A. Dietary fat-influenced development of colon neoplasia in Apc Min mice exposed to benzo(a)pyrene. Toxicol Pathol 2009;37(7):938-46.

26. Yanagisawa R, Koike E, Win-Shwe TT, Yamamoto M, Takano H. Impaired lipid and glucose homeostasis in hexabromocyclododecane-exposed mice fed a high-fat diet. Environ Health Perspect 2014;122(3):277-83.

27. McGill HC, Jr., McMahan CA, Gidding SS. Preventing heart disease in the 21st century: implications of the Pathobiological Determinants of Atherosclerosis in Youth (PDAY) study. Circulation 2008;117(9):1216-27.

28. Perkins JT, Petriello MC, Newsome BJ, Hennig B. Polychlorinated biphenyls and links to cardiovascular disease. Environ Sci Pollut Res Int 2016;23(3):2160-72.

29. Petriello MC, Han SG, Newsome BJ, Hennig B. PCB 126 toxicity is modulated by cross-talk between caveolae and Nrf2 signaling. Toxicol Appl Pharm 2014;277(2):192-9.

30. Petriello MC, Newsome B, Hennig B. Influence of nutrition in PCB-induced vascular inflammation. Environ Sci Pollut Res Int 2014;21(10):6410-8.

31. Senthong V, Li XS, Hudec T, Coughlin J, Wu Y, et al. Plasma trimethylamine $\mathrm{N}$-oxide, a gut microbe-generated phosphatidylcholine metabolite, is associated with atherosclerotic burden. J Am Coll Cardiol 2016;67(22):2620-8.

32. Bennett BJ, de Aguiar Vallim TQ, Wang Z, Shih DM, Meng Y, et al. Trimethylamine-N-oxide, a metabolite associated with atherosclerosis, exhibits complex genetic and dietary regulation. Cell Metab 2013;17(1):49-60.

33. Brown JM, Hazen SL. The gut microbial endocrine organ: bacterially derived signals driving cardiometabolic diseases. Annu Rev Med 2015;66:343-59.

34. Seldin MM, Meng Y, Qi H, Zhu W, Wang Z, et al. Trimethylamine $\mathrm{N}$-oxide promotes vascular inflammation through signaling of mitogen-activated protein kinase and nuclear factor-kappaB. J Am Heart Assoc 2016;5(2). pii: e002767.

35. Senthong V, Wang Z, Li XS, Fan Y, Wu Y, et al. Intestinal microbiota-generated metabolite trimethylamine- $\mathrm{N}$-oxide and 5-year mortality risk in stable coronary artery disease: the contributory role of intestinal microbiota in a courage-like patient cohort. J Am Heart Assoc 2016;5(6). pii: e002816.

36. Petriello MC, Hoffman JB, Sunkara M, Wahlang B, Perkins JT, et al. Dioxin-like pollutants increase hepatic flavin containing monooxygenase (FMO3) expression to promote synthesis of the pro-atherogenic nutrient biomarker trimethylamine $\mathrm{N}$-oxide from dietary precursors. J Nutr Biochem 2016;33:145-53.

37. Majkova Z, Layne J, Sunkara M, Morris AJ, Toborek M, et al. Omega-3 fatty acid oxidation products prevent vascular endothelial cell activation by coplanar polychlorinated biphenyls. Toxicol Appl Pharm 2011;251(1):41-9.

38. Newsome BJ, Petriello MC, Han SG, Murphy MO, Eske KE, et al. Green tea diet decreases PCB 126-induced oxidative stress in mice by up-regulating antioxidant enzymes. J Nutr Biochem 2014;25(2):126-35.

39. Petriello MC, Newsome BJ, Dziubla TD, Hilt JZ, Bhattacharyya D, et al. Modulation of persistent organic pollutant toxicity through nutritional intervention: emerging opportunities in biomedicine and environmental remediation. Sci Total Environ 2014;491492:11-6.

40. Romieu I, Garcia-Esteban R, Sunyer J, Rios C, Alcaraz-Zubeldia M, et al. The effect of supplementation with omega-3 polyunsaturated fatty acids on markers of oxidative stress in elderly exposed to PM(2.5). Environ Health Perspect 2008;116(9):1237-42.

41. Slim R, Toborek M, Robertson LW, Hennig B. Antioxidant protection against PCB-mediated endothelial cell activation. Toxicol Sci 1999;52(2):232-9.

42. Sun TL, Liu Z, Qi ZJ, Huang YP, Gao XQ, et al. (-)-Epigallocatechin3-gallate (EGCG) attenuates arsenic-induced cardiotoxicity in rats. Food Chem Toxicol 2016;93:102-10.

43. Tong H, Rappold AG, Diaz-Sanchez D, Steck SE, Berntsen J, et al. Omega-3 fatty acid supplementation appears to attenuate particulate air pollution-induced cardiac effects and lipid changes in healthy middle-aged adults. Environ Health Perspect 2012;120(7):952-7.

44. Guida N, Laudati G, Anzilotti S, Secondo A, Montuori P, et al. Resveratrol via sirtuin-1 downregulates RE1-silencing transcription factor (REST) expression preventing PCB-95-induced neuronal cell death. Toxicol Appl Pharm 2015;288(3):387-98.

45. Baker NA, English V, Sunkara M, Morris AJ, Pearson KJ, et al. Resveratrol protects against polychlorinated biphenyl-mediated impairment of glucose homeostasis in adipocytes. J Nutr Biochem 2013;24(12):2168-74.

46. Siriwardhana N, Kalupahana NS, Moustaid-Moussa N. Health benefits of $n-3$ polyunsaturated fatty acids: eicosapentaenoic acid and docosahexaenoic acid. Adv Food Nutr Res 2012;65:211-22.

47. Swanson D, Block R, Mousa SA. Omega-3 fatty acids EPA and DHA: health benefits throughout life. Adv Nutr 2012;3(1):1-7.

48. Sofi F, Cesari F, Abbate R, Gensini GF, Casini A. Adherence to Mediterranean diet and health status: meta-analysis. Br Med J 2008;337:a1344.

49. Turunen AW, Jula A, Suominen AL, Mannisto S, Marniemi J, et al. Fish consumption, omega-3 fatty acids, and environmental contaminants in relation to low-grade inflammation and early atherosclerosis. Environ Res 2013;120:43-54.

50. Murphy MO, Petriello MC, Han SG, Sunkara M, Morris AJ, et al. Exercise protects against $\mathrm{PCB}$-induced inflammation and 
associated cardiovascular risk factors. Environ Sci Pollut Res Int 2016;23(3):2201-11.

51. Choi JJ, Eum SY, Rampersaud E, Daunert S, Abreu MT, et al. Exercise attenuates PCB-induced changes in the mouse gut microbiome. Environ Health Perspect 2013;121(6):725-30.

52. Round JL, Mazmanian SK. The gut microbiota shapes intestinal immune responses during health and disease. Nat Rev Immunol 2009;9(5):313-23.

53. Kinross JM, Darzi AW, Nicholson JK. Gut microbiome-host interactions in health and disease. Genome Med 2011;3(3):14.

54. Tremaroli V, Backhed F. Functional interactions between the gut microbiota and host metabolism. Nature 2012;489(7415):242-9.

55. Arguin H, Sanchez M, Bray GA, Lovejoy JC, Peters JC, et al. Impact of adopting a vegan diet or an olestra supplementation on plasma organochlorine concentrations: results from two pilot studies. Br J Nutr 2010;103(10):1433-41.

56. Jandacek RJ, Genuis SJ. An assessment of the intestinal lumen as a site for intervention in reducing body burdens of organochlorine compounds. ScientificWorldJ 2013;2013:205621.

57. Jandacek RJ, Tso P. Enterohepatic circulation of organochlorine compounds: a site for nutritional intervention. J Nutr Biochem 2007;18(3):163-7.

58. Jandacek RJ, Heubi JE, Buckley DD, Khoury JC, Turner WE, et al. Reduction of the body burden of PCBs and DDE by dietary intervention in a randomized trial. J Nutr Biochem 2014;25(4):483-8.

59. Jandacek RJ, Rider T, Keller ER, Tso P. The effect of olestra on the absorption, excretion and storage of 2,2',5,5' tetrachlorobiphenyl; 3,3',4,4' tetrachlorobiphenyl; and perfluorooctanoic acid. Environ Int 2010;36(8):880-3.

60. Jandacek RJ, Anderson N, Liu M, Zheng S, Yang Q, et al. Effects of yo-yo diet, caloric restriction, and olestra on tissue distribution of hexachlorobenzene. Am J Physiol Gastrointest Liver Physiol 2005;288(2):G292-9.

61. Jandacek RJ. Intervention to reduce PCBs: learnings from a controlled study of Anniston residents. Environ Sci Pollut Res Int 2016;23(3):2022-6.

62. Moser GA, McLachlan MS. A non-absorbable dietary fat substitute enhances elimination of persistent lipophilic contaminants in humans. Chemosphere 1999;39(9):1513-21.

63. Egger G, Liang G, Aparicio A, Jones PA. Epigenetics in human disease and prospects for epigenetic therapy. Nature 2004;429(6990):457-63.

64. Chuang JC, Jones PA. Epigenetics and microRNAs. Pediatr Res 2007;61(5 Pt 2):24R-9R.

65. Vrijens K, Bollati V, Nawrot TS. MicroRNAs as potential signatures of environmental exposure or effect: a systematic review. Environ Health Perspect 2015;123(5):399-411.

66. Liu D, Perkins JT, Petriello MC, Hennig B. Exposure to coplanar $\mathrm{PCBs}$ induces endothelial cell inflammation through epigenetic regulation of NF-kappaB subunit p65. Toxicol Appl Pharm 2015;289(3):457-65.

67. Deng Q, Dai X, Guo H, Huang S, Kuang D, et al. Polycyclic aromatic hydrocarbons-associated microRNAs and their interactions with the environment: influences on oxidative DNA damage and lipid peroxidation in coke oven workers. Environ Sci Technol 2014;48(7):4120-8.

68. Hou L, Barupal J, Zhang W, Zheng Y, Liu L, et al. Particulate air pollution exposure and expression of viral and human microRNAs in blood: the Beijing truck driver air pollution study. Environ Health Perspect 2016;124(3):344-50.

69. Wahlang B, Petriello MC, Perkins JT, Shen S, Hennig B. Polychlorinated biphenyl exposure alters the expression profile of microRNAs associated with vascular diseases. Toxicol In Vitro 2016;35:180-7.

70. Rozek LS, Dolinoy DC, Sartor MA, Omenn GS. Epigenetics: relevance and implications for public health. Annu Rev Publ Health 2014;35:105-22.

71. Ayissi VB, Ebrahimi A, Schluesenner H. Epigenetic effects of natural polyphenols: a focus on SIRT1-mediated mechanisms. Mol Nutr Food Res 2014;58(1):22-32.

72. Ross SA, Davis CD. The emerging role of microRNAs and nutrition in modulating health and disease. Annu Rev Nutr 2014;34:305-36.

73. Yun JM, Jialal I, Devaraj S. Epigenetic regulation of high glucoseinduced proinflammatory cytokine production in monocytes by curcumin. J Nutr Biochem 2011;22(5):450-8.

74. Liu D, Perkins JT, Hennig B. EGCG prevents PCB-126-induced endothelial cell inflammation via epigenetic modifications of NFkappaB target genes in human endothelial cells. J Nutr Biochem 2016;28:164-70.

75. Barres R, Yan J, Egan B, Treebak JT, Rasmussen M, et al. Acute exercise remodels promoter methylation in human skeletal muscle. Cell Metab 2012;15(3):405-11.

76. Davalos A, Goedeke L, Smibert P, Ramirez CM, Warrier NP, et al. miR-33a/b contribute to the regulation of fatty acid metabolism and insulin signaling. Proc Natl Acad Sci USA 2011;108(22):9232-7.

77. Pareja-Galeano H, Sanchis-Gomar F, Garcia-Gimenez JL. Physical exercise and epigenetic modulation: elucidating intricate mechanisms. Sports Med 2014;44(4):429-36.

78. Yang Z, Cappello T, Wang L. Emerging role of microRNAs in lipid metabolism. Acta Pharm Sin B 2015;5(2):145-50.

79. Monsalve FA, Pyarasani RD, Delgado-Lopez F, Moore-Carrasco R. Peroxisome proliferator-activated receptor targets for the treatment of metabolic diseases. Mediat Inflamm 2013;2013:549627.

80. Huang CW, Chien YS, Chen YJ, Ajuwon KM, Mersmann HM, et al. Role of $n-3$ polyunsaturated fatty acids in ameliorating the obesity-induced metabolic syndrome in animal models and humans. Int J Mol Sci 2016;17(10). pii: E1689.

81. Heijmans BT, Tobi EW, Stein AD, Putter H, Blauw GJ, et al. Persistent epigenetic differences associated with prenatal exposure to famine in humans. Proc Natl Acad Sci USA 2008;105(44):17046-9.

82. Soubry A, Murphy SK, Wang F, Huang Z, Vidal AC, et al. Newborns of obese parents have altered DNA methylation patterns at imprinted genes. Int J Obes (Lond) 2015;39(4):650-7.

83. Vickers MH. Early life nutrition, epigenetics and programming of later life disease. Nutrients 2014;6(6):2165-78. 